\title{
Electromagnetic background noise at L'Aquila Geomagnetic Observatory
}

\author{
Lucia Santarelli ${ }^{1, \star}$, Paolo Palangio ${ }^{1}$, Marcello De Lauretis ${ }^{2}$ \\ ${ }^{1}$ Istituto Nazionale di Geofisica e Vulcanologia, L'Aquila, Italy \\ ${ }^{2}$ Università degli Studi dell'Aquila, Dipartimento di Scienze Fisiche e Chimiche, L'Aquila, Italy
}

\section{Article history}

Received February 8, 2013; accepted December 19, 2013.

Subject classification:

Electromagnetic noise by railways, Man-made electromagnetic noise, Quiet days noise analysis, Man-made disturbances on ULF measurements.

\begin{abstract}
In this paper we analyze the electromagnetic background noise at L'Aquila Geomagnetic Observatory during 2006 and 2007 in the frequency band 1-100 $\mathrm{mHz}$. In this band a pronounced daily variation is observed both in the natural signals as well as in the artificial ones, giving rise to the problem of separating different contributions of very similar morphology. We analyzed periods when the local $\mathrm{K}$ index was approximately zero, in correspondence with minimum of the magnetospheric and ionospheric activity. We found that in our area the main source of artificial noise is constituted by the DC electrified railways.
\end{abstract}

\section{Introduction}

In the frequency band $10^{-3}-10^{5} \mathrm{~Hz}$ a wide variety of electromagnetic natural phenomena are observed without significant changes during last millions years. All living organisms appeared and evolved into this background radiation.

The natural electromagnetic soupe (Figures 1 and 2) can be observed at any point on the terrestrial surface and is the result of an enormous number of signals produced by different sources in the magnetosphere and its interaction with the solar wind, the ionosphere, the Earth-ionosphere cavity and the Earth's interior. This background permeates the near Earth environment in a complex manner involving, for example:

(1) free oscillation modes of the magnetospheric cavity $(0.001 \mathrm{~Hz}-0.01 \mathrm{~Hz})$ [Campbell 1997].

(2) resonance modes of the alfvenic cavity $(0.1 \mathrm{~Hz}$ $10 \mathrm{~Hz}$ ) [Belyaev et al. 1990].

(3) emissions associated with various instability processes in the magnetospheric and ionospheric plasma (0.001 Hz-100 kHz) [Campbell 1997].

(4) emissions associated with tectonic and volcanic phenomena $(0.001 \mathrm{~Hz}-1000 \mathrm{~Hz})$ [Palangio et al. 2007].

(5) magnetic storms and associated phenomena
(0.0001 Hz-1 Hz) [Campbell 1997].

Some aspects of magnetospheric dynamics such as wave propagation, resonance phenomena, global oscillation modes, request simultaneous measurements from large magnetometer networks, often installed in highly populated regions. As a consequence, a careful evaluation of the possible contamination of man-made disturbances on ULF measurements represents an important topic in a wide scientific context.

The main sources of artificial EM noise in the frequency bands of interest are railways transport systems on rails (underground trains, trams, trolley buses), electrical energy distribution plants, industrial plants etc. These sources, owing to their spatial extent, affect vast, heavily populated areas. There are also local sources of smaller scale signals as, for example, technological devices daily used worldwide. The artificial emissions contributed to the primordial broth only during the last century, and their influence on ULF measurements have been discussed by several authors.

Fraser and Ellyett [1964] found that the amplitude of small fluctuations of the Earth's magnetic field (the geomagnetic micropulsations [Jacobs 1970]) was influenced by magnetic signatures associated with the electrical network up to a distance of about 15 miles from the city (practically all micropulsation activity under observing conditions strongly decreased on Sunday, providing a simple test for man-made influences). An isolated dc electric train system, although dozens of miles away, is able to produce pulsations of large amplitude on a wide-band micropulsation recorder, which can be confused with natural signals.

During the recording of the ULF signals FraserSmith and Coates [1978] observed the simultaneous occurrence of large-amplitude ULF signals and the ar- 


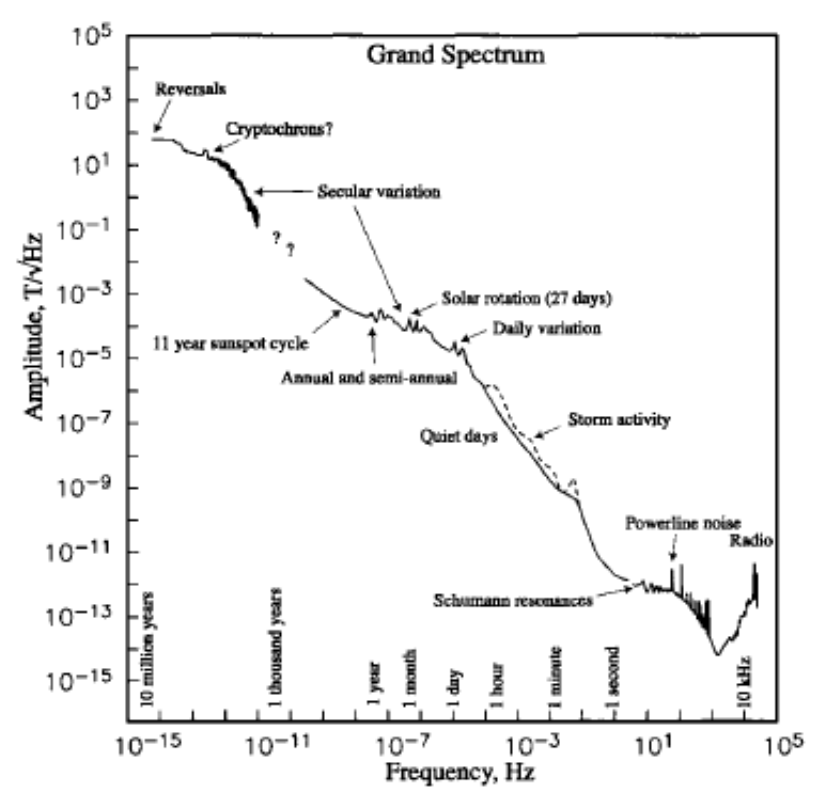

Figure 1. Power spectra of the variations of the geomagnetic field (adopted from Constable and Constable [2004]).

rival/ departure of San Francisco Bay Area Rapid Transit (BART) trains at nearby Stanford station. Later comparison of the occurrence of the ULF interference at the Stanford field site with the trains track confirmed that the source of the interference was the BART system. Fraser and Coates therefore identified the BART system as a powerful and potentially completely specified source of ULF wave generation which could be useful to explain some of the properties of the naturally occurring ULF signals.

In contrast to their irregularity over time intervals of few minutes, the BART magnetic signals were distinctly regular in their daily and weekly occurrence; the train service at each station was reduced during nighttime and also the magnetic activity was weaker in the same hours. Fraser and Coates drawn attention to other possible sources of ULF electromagnetic fields; in addi-

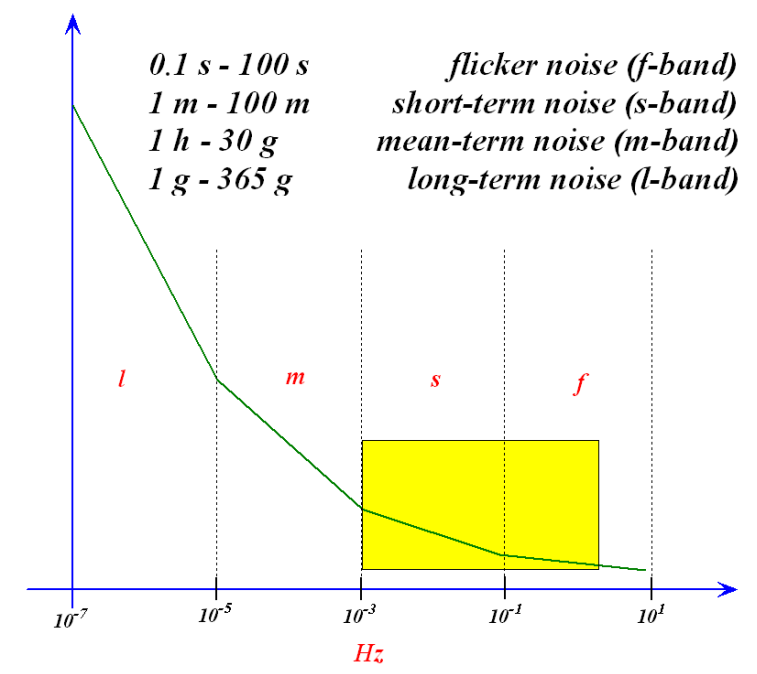

Figure 2. The power spectrum, in arbitrary units, of different geomagnetic noise bands [Jacobs 1970]. tion to other rapid train transit systems, these possible sources include high-voltage dc power transmission lines, electric railways using dc power and dc-powered mine haulage systems.

In observatories numerous noise investigation were carried out; many of them are collected in the paper of Burkhart [1951] for Furstenfeldbruck, Mikerina [1962] for Voyeykovo observatory, Miguel [1964] for Toledo, Märcz and Verö [1970] for Nagycenk.

In Italy, in their study about the effects of the electromagnetic field produced by electrification of railway Sangritana (between Castel di Sangro and Lanciano, in Abruzzo region) on the magnetotelluric observatory of Villa Santa Maria (Chieti), Palangio et al. [1991] described a simple model of currents and electromagnetic fields distribution near railway track; they found that the electromagnetic background noise was much intense on the vertical component $Z$, with amplitudes between 10 and $15 \mathrm{nT}$; they also calculated the absolute value of the electric noise with an amplitude between 10 and $20 \mathrm{mV} / \mathrm{km}$.

In order to investigate the possible disappearance (or significant reduction) of the man-made contamination during short intervals in the middle of the night, Villante et al. [2004] conducted the same kind of analysis for different time intervals in the nighttime sector.

The reduced power level found during short time intervals in the middle of the night and during weekend can be imputed to the much less intense train traffic. Villante et al. also conducted an analysis at Antarctic latitudes, and their observations do not support any firm evidence for a significant man-made contamination in ULF band, suggesting a negligible influence on remote areas.

From all these papers it is evident that the artificial signals contributed to the electromagnetic background noise, masking part of the natural signal. The choice of the location of the measurements requires then an awareness of the local artificial background noise, achieved through a detailed surveying of the territory.

The spatial extension of the magnetospheric signals is of the order of hundreds of kilometers, while that of the artificial sources of tens of kilometers. This diffeence reflects the gradiometric properties of the inducted fields. In order to evaluate the different contributions it is also necessary to consider the geometry of source-observer and the electrical properties of the subsoil [Szarka 1988, Junge 1996]. For example the L'Aquila observatory is permeated by artificial sources of different nature: industrial and man-made noise in a radius of about $10 \mathrm{~km}$, railway generated noise about $30 \mathrm{~km}$ (see Figure 3 ) and the natural signals over hundreds $\mathrm{km}$. The subsoil resistivity integrated on the first $50 \mathrm{~km}$ is of approximately $800 \Omega \mathrm{m}$, as showed in Figure 4 [Di Lorenzo et 

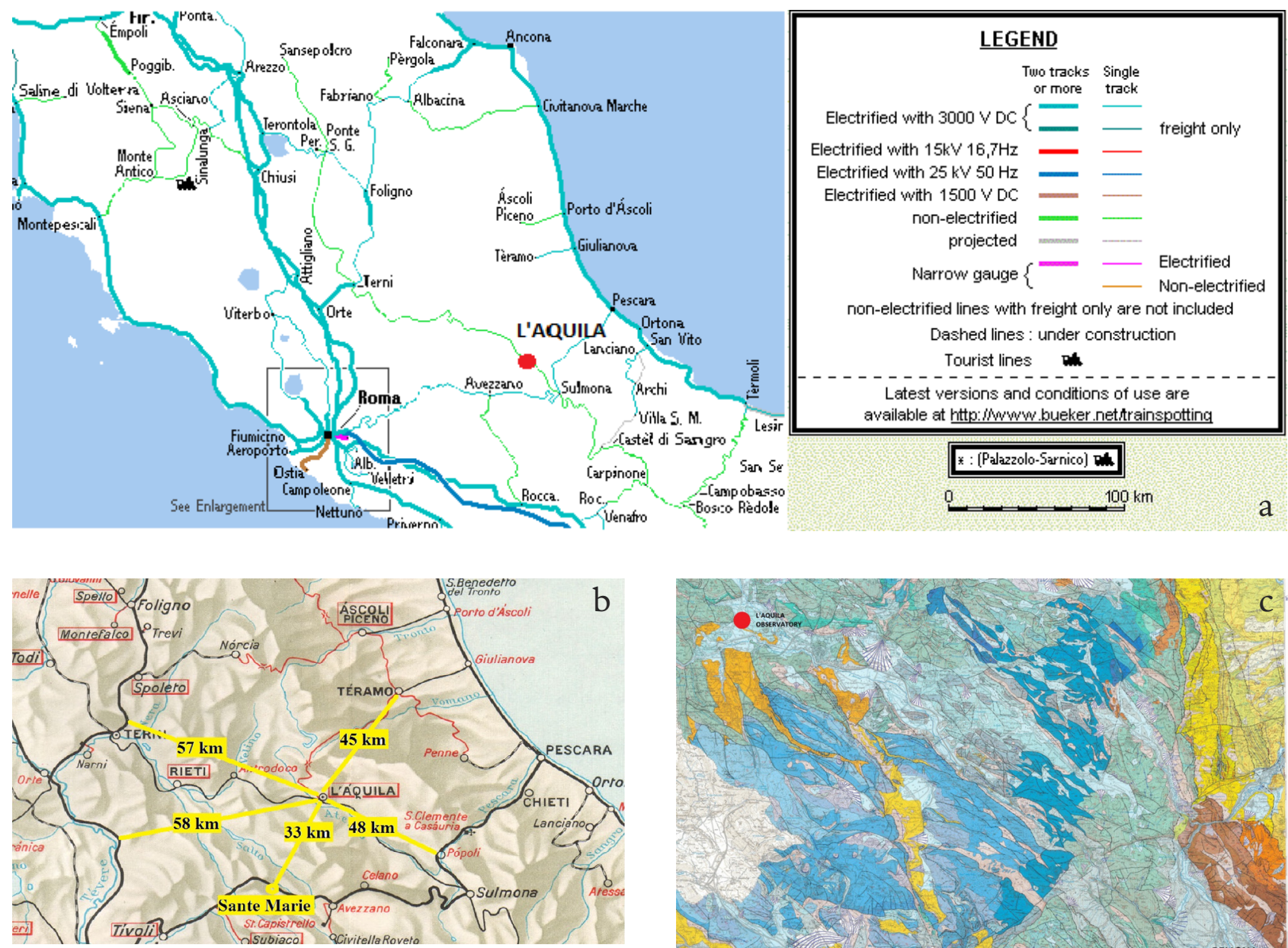

Figure 3. (a) Railway map of Central Italy. The DC electrified railway line that mainly interferes with L'Aquila Geomagnetic Observatory is Roma-Sulmona-Pescara in light blue colour; at the contrary the Terni-L'Aquila-Sulmona line, in green, it does not disturb the magnetometers because is not electrified (diesel power). (b). Minimum distances of L'Aquila Geomagnetic Observatory from the nearest DC electrified railways (Sante Marie station is the

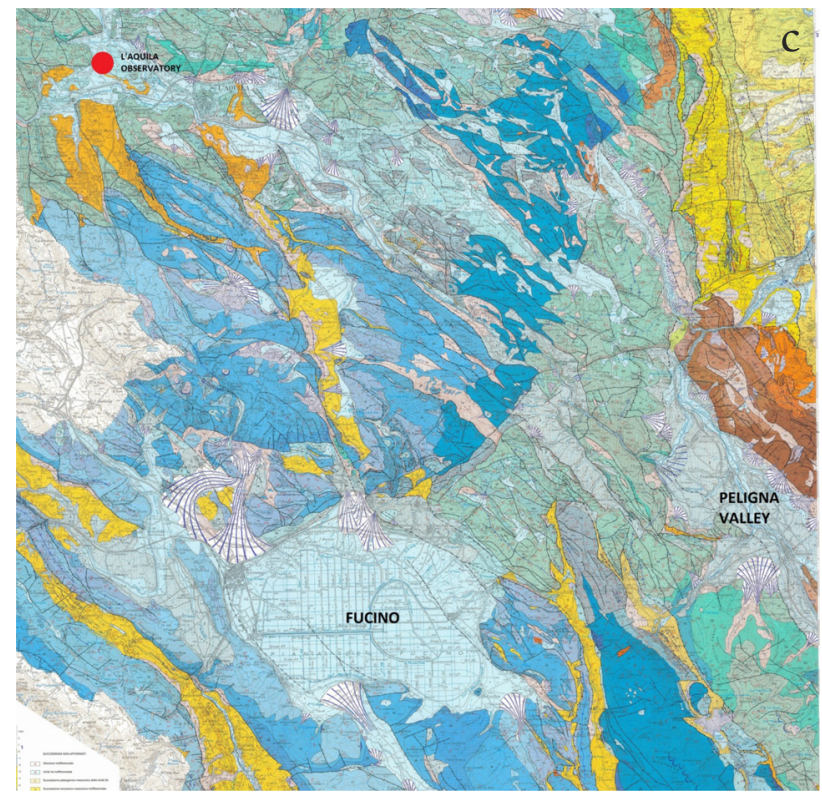
nearest one at $33 \mathrm{~km}$ ). The railway line that contributes most to the noise at L'Aquila observatory is that from Sante Marie to Popoli, in particular from Avezzano to Pescina in the flat Fucino (Marsica site) due to the high electrical conductivity of lacustrine sediments and clay deposits in the subsoil; in fact the wide basin of Fucino until 1875 was a lake, the third largest of Italy. (c). Geological map of Abruzzo [Vezzani and Ghisetti 1996]: the position of L'Aquila observatory is indicated in the upper left by the red point. In the bottom center the position of Fucino is represented by light blue color and with similar color the Peligna Valley in the lower right.

al. 2011], and the time and the frequency distribution of the noise allow us to identify several frequency bands where different noise pattern appear. In Figure 4 the ground electric resistivity profile is obtained using a conventional magnetotelluric approach [Constable et al. 1987] using, for the inversion, both the apparent resistivity and the phase; the profile shown in Figure 4 was obtained using only the two horizontal components of magnetic field and the two horizontal components of the telluric field.

\section{Measurements and data analysis}

The Geomagnetic Observatory is located at Masseria Calore, on a flat ground between the villages of San Vittorino and Preturo, at about ten kilometers
North-West from the city of L'Aquila. The geographic latitude is $42^{\circ} 23 \mathrm{~N}$, the geographic longitude is $13^{\circ} 19^{\prime} \mathrm{E}$; the geomagnetic coordinates: $36^{\circ} 14^{\prime} \mathrm{N}$, $87^{\circ} 01^{\prime} \mathrm{E}$; the corrected geomagnetic coordinates: $36.3^{\circ} \mathrm{N}, 87.3^{\circ} \mathrm{E}$; the shell-parameter $\mathrm{L} \sim 1.6$ and the height above sea level is $682 \mathrm{~m}$. The observatory includes the buildings for absolute measurements, variometers, proton precession vector magnetometer, laboratory and general services.

The variometers are: a proton precession vector magnetometer for the measurement of the $\mathrm{H}, \mathrm{D}, \mathrm{Z}$ elements and total magnetic field $\mathrm{F}$ with a $0.1 \mathrm{nT}$ resolution; two triaxial fluxgate magnetometers, one with toroidal and the other with linear shaped sensors and a biaxial fluxgate magnetometer for the measurements 


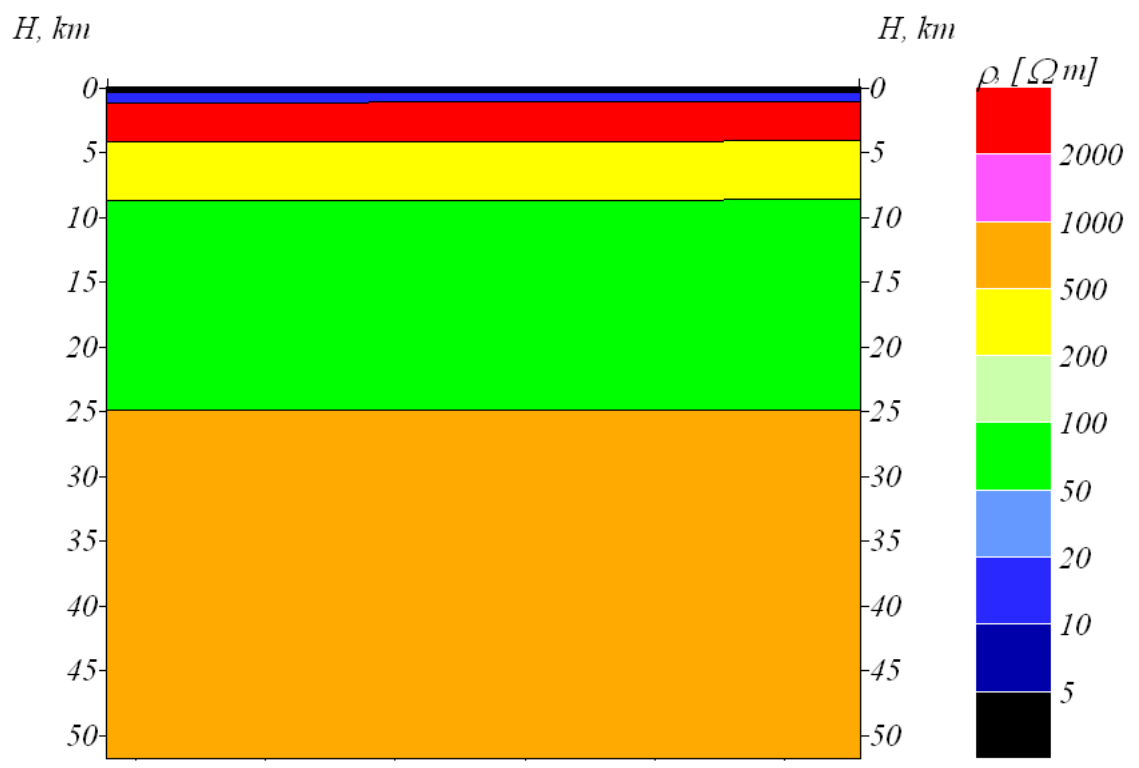

Figure 4. Structure of electric conductivity under the observatory (adopted from Di Lorenzo et al. [2011]).

of $\mathrm{D}$ and I, supported by a proton magnetometer for the measurement of $\mathrm{F}$.

Routine studies at Geomagnetic Observatory regard magnetic field of external sources, magnetotelluric investigations [Mikerina 1962, Qian and Pedersen 1991], study of the electric conductivity of the subsoil by means of Geomagnetic Deep Sounding (GDS) techniques and study of the electromagnetic field linked to the geodynamics processes [Egbert et al. 2000].

The magnetic noise hardly affects the pursuit of these objectives. Both background local artificial noise and the signals of external origin are characterized by a large diurnal fluctuation with a remarkable consistency of phase [Jones and Kelly 1966]. A partial discrimination between the two contributions can be made in correspondence with changes in daylight saving time, because the local artificial noise follows the change, while the external signals are unaffected by such variation.

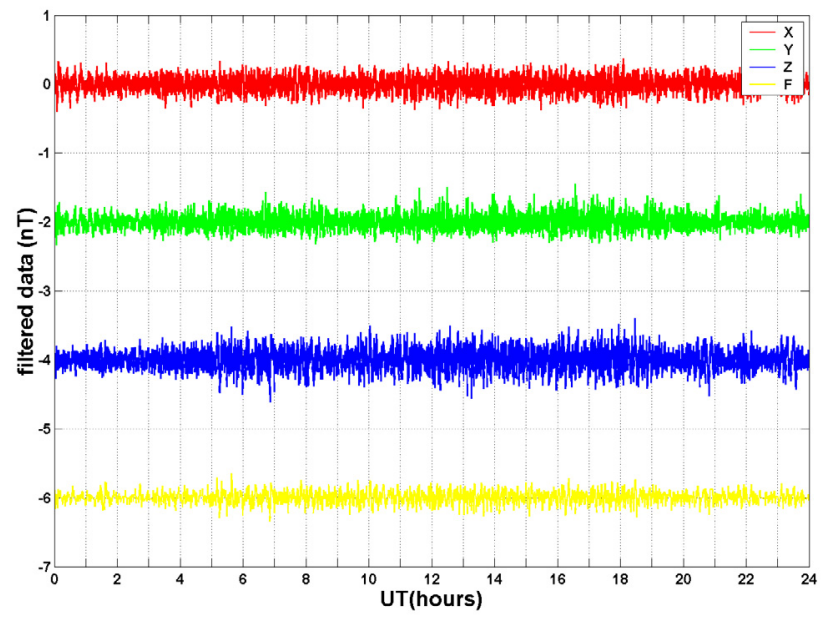

Figure 5. Example of geomagnetic filtered data (components X, Y, $\mathrm{Z}$ and total intensity field $\mathrm{F}$ ) relative to a selected day with local $\mathrm{K}$ index approximately zero.
The Earth's magnetic field undergoes different temporal variations, with periods from fractions of second to millions of years [Constable et al. 1987, Constable and Constable 2004].

The geomagnetic band can be divided into four sub-bands (see Figure 2) characterized by different statistical and spectral proprieties. In the " $\mathrm{f}$ " band (flicker noise), the noise approaches a slope typical of the white noise, while in the band "l" there is the maximum slope, that is the $\alpha$ coefficient is higher. Our studies are focused on the " $\mathrm{s}$ " and " $\mathrm{f}$ " bands in which the natural dominating signals are the geomagnetic micropulsations [Jacobs 1970, Verö 1986, Yumoto 1988].

In order to separate the noise from the signal, we analyzed periods when the local $\mathrm{K}$ index was approximately zero, in correspondence to magnetospheric and ionospheric activity minimum.

For this analysis we used $1 \mathrm{~s}$ measurements of the geomagnetic field components recorded at the Geomagnetic Observatory of L'Aquila during two years, 2006-2007.

Figure 5 shows an example of geomagnetic field data measured in the observatory. They have been filtered by a 4th order high-pass digital Chebyshev filter with a cutoff frequency of $1 \mathrm{mHz}$; data are relative to one of the selected day with local $\mathrm{K}$ index approximately zero (January 13, 2007), and this example day is analyzed from Figure 5 to Figure 15. In particular the amplitude of the fluctuations of the $Z$ component presents the typical daily variation with minimum around the local midnight and maximum around noon. This trend is a common feature of both the environmental noise and the magnetospheric signal [Villante et al. 2004]. The fact that this behaviour is more evident in the $Z$ component with respect to the horizontal ones reflects 
the fact that the $Z$ component depends very much on the environmental noise and is scarcely influenced by the external sources [Fraser and Ellyett 1964, Jones and Kelly 1966, Palangio et al. 1991]. These assertions are based on two hypothesis:

(1) the magnetic external field $Z$ component is null because the ionospheric currents act approximately as a current layer that lies in horizontal plane approximately parallel to the terrestrial surface.

(2) on the surface of a semi-infinite conductor the possible variations of magnetic field that is external to the surface are null because the induced magnetic field in the conductor cancel the primary inducing magnetic field.

For these reasons the fluctuations on the $Z$ component can be representative of the noise.

Then, in a case of zero electric resistivity, the variations on the $Z$ component is null and the variation of the horizontal components are doubled. In the real case the situation is intermediate, so a small residual is present, depending on the structure of Earth's electric conductivity (Figure 4); the estimation of the integrated resistivity (assuming that the resistivity varies only with the $Z$ component in a layer of thickness 1 ) of the observatory subsoil, $\rho=1 / 1 \int \rho(z) d z$, gives a value of about $800 \Omega^{*} \mathrm{~m}$ [Di Lorenzo et al. 2011]. This value fix the boundary between the frequency band where there is not electromagnetic interaction with the subsoil and the band where the noise interact with the soil for each value of the source-observatory distance.

From the diffusion equation [Jackson 1975] we have:

$$
\tau_{\mathrm{d}}=\mu \sigma \mathrm{D}^{2} \text { and } \mathrm{f}_{\mathrm{d}}=1 / \mu \sigma \mathrm{D}^{2}
$$

where $\tau_{d}$ is the diffusion time constant and $D$ is the thickness of the conductor, $\sigma$ is the electrical conductivity equal to $1 / \rho, \mu$ is the magnetic permeability and $f_{d}$ is the diffusion frequency.

For example if we consider the regional electrified railways that are far from the observatory about $40 \mathrm{~km}$ we have:

$\tau_{d} \approx 2 \mathrm{~s}$ that corresponds approximately to $\mathrm{f}_{\mathrm{d}}=0.5 \mathrm{~Hz}$.

For $\mathrm{f}<0.5 \mathrm{~Hz}$ the noise does not interact with the soil and it is indistinguishable from the signal.

For $\mathrm{f}>0.5 \mathrm{~Hz}$ the noise interacts with the soil and it is separable from the signal.

So it is possible to subdivide the frequency band in two region, the first (low frequencies) in which the effect of the subsoil is negligible and the second one in which the signals of external origin are modified (in amplitude and phase) in a manner depending on the frequency.

In Figure 6 the power spectra of the geomagnetic

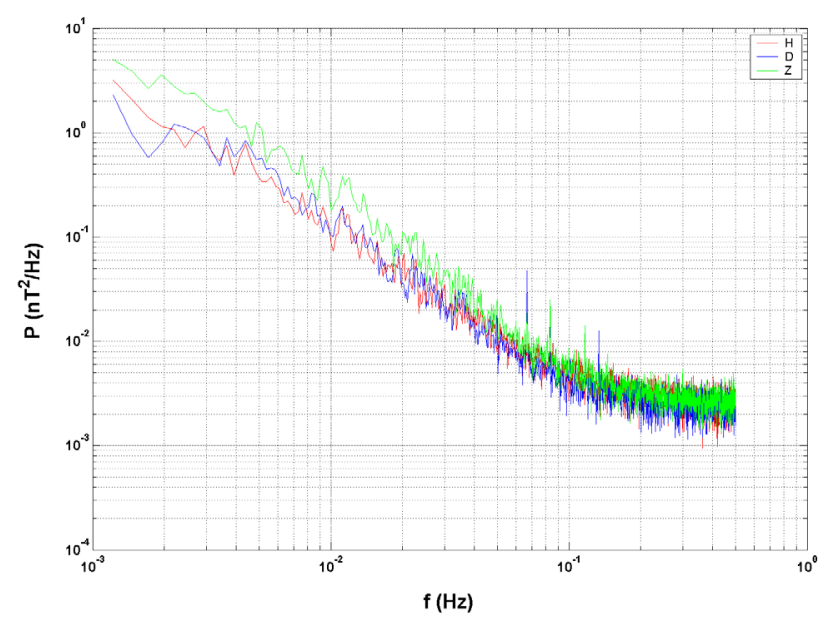

Figure 6. Power spectra of the geomagnetic field components in logarithmic scale.

field components in logarithmic scale are presented. The power spectra show two different trends, with the low frequency portion characterized by a higher spectral slope and the other approximately constant with the frequency. The first frequency range (DC-100 mHz) looks like red noise, while the second one (over $100 \mathrm{mHz}$ ) is typical of white noise, with thermal characteristics. The first spectral region corresponds to natural signals of external origin, while the high frequency portion, in which the spectral density is almost constant, may be related to instrumental noise. The knee of the curve is known as
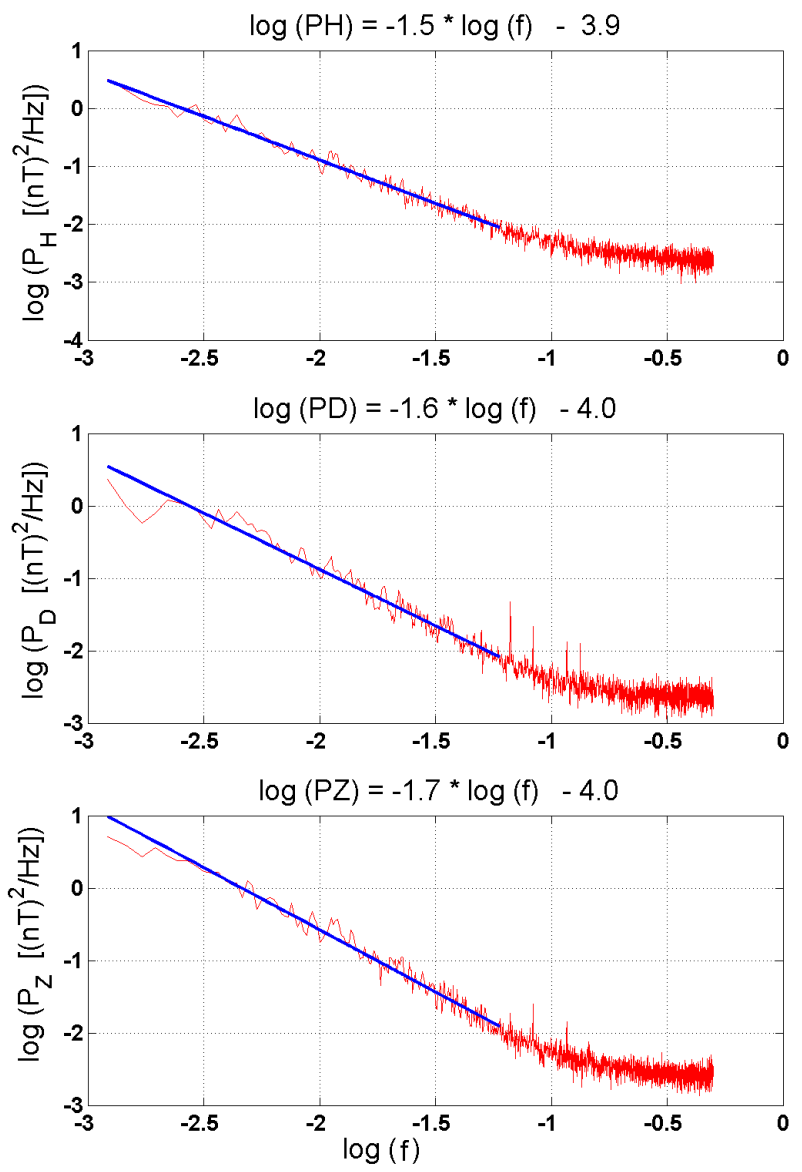

Figure 7. Spectra fit of geomagnetic field components. 
"noise knee", and marks the transition between the two regions, characterized by two different kind of induction.

Figure 7 shows spectra fit; we have calculated spectra fit and relative coefficients in the frequency band 1$100 \mathrm{mHz}$. The horizontal components are characterized by a spectral index $\alpha \sim 1.5$, while the vertical one by $\alpha \sim 1.7$. This figure shows that the $Z$ slope is appreciably higher than that of the other component's spectra (in accordance with Palangio et al. [1991]), possibly due to the influence of the conductivity structure of the subsoil. The Earth behaves as a low-pass filter that attenuates highest frequencies, increasing then the slope of the spectrum.

Figure 8 shows the square modulus of cross spectra between the three components of geomagnetic field; from this figure results that in the frequency band $10^{-3}$ $10^{-1} \mathrm{~Hz}$ the highest values regard the $\mathrm{x}$ and $\mathrm{z}$ components, and increase with the decreasing of the frequency.

Figure 9 shows the results of the coherence analysis between the three components of the geomagnetic field. Similarly to Figure 8, it is evident that the $x z$ and xy coherence overcomes that of $y z$, always in particular in the $1-100 \mathrm{mHz}$ band. The correlation between East-
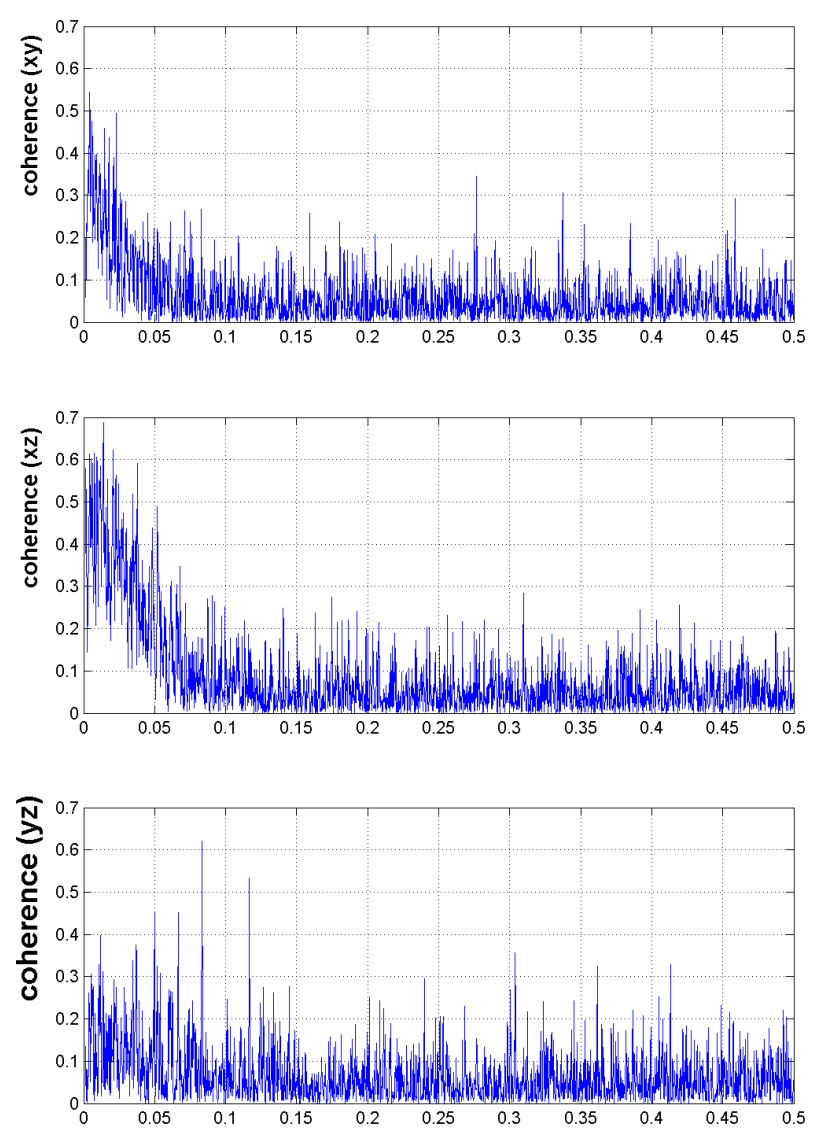

$f(H z)$

Figure 9. Coherence analysis between the three components of geomagnetic field.

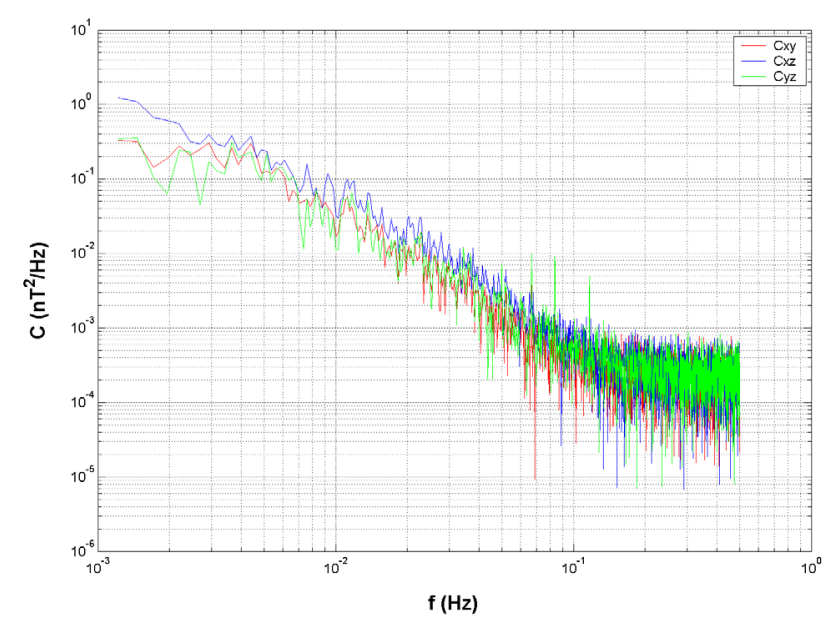

Figure 8. Cross spectra between the three components of geomagnetic field.

West and the vertical component is very low, indicating that these components are almost independent; it means that in the yz plane various sources of noise act not correlated each other.

Figure 10 and Figure 11 show the polarization analysis [Fowler et al. 1967] of the horizontal components, where $\rho$ is the polarization degree, $\varepsilon$ is the ellipticity and $\theta$ is the orientation i.e. the inclination of the
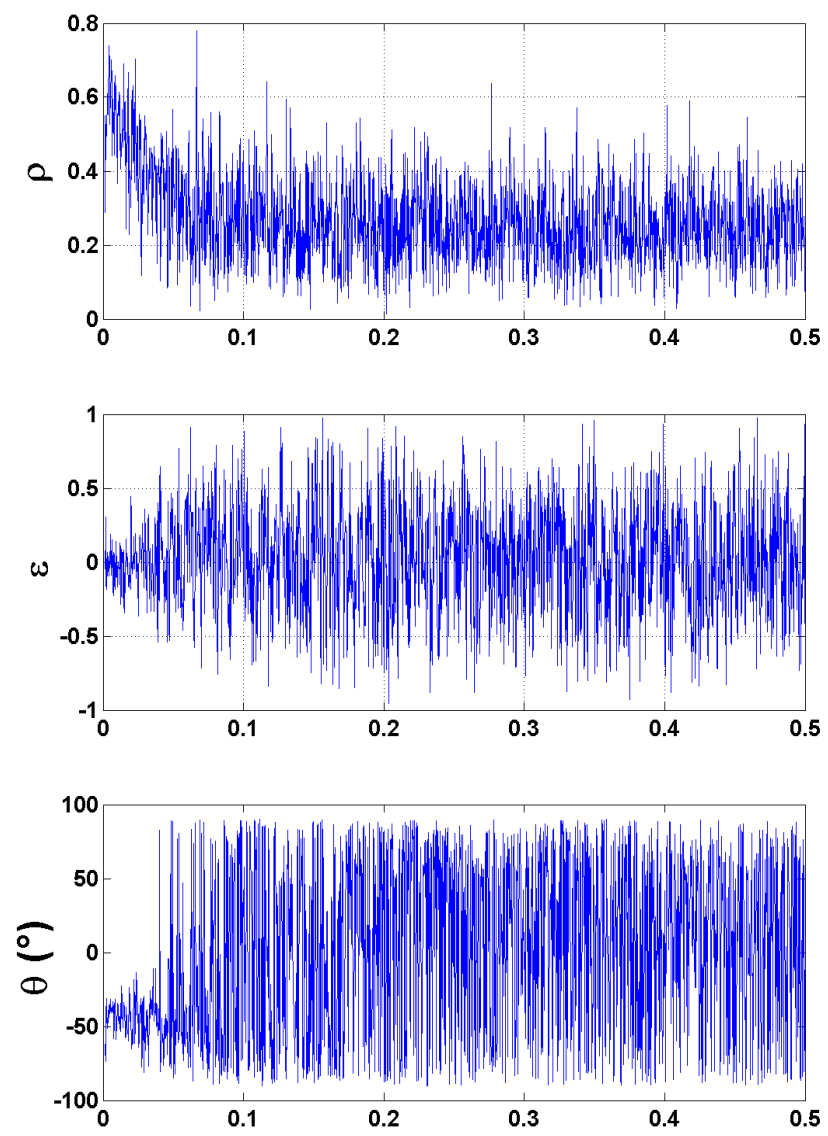

$f(H z)$

Figure 10. Polarization analysis of the horizontal components of geomagnetic field. 
major axis of the ellipse as shown in Figure 12.

Above $100 \mathrm{mHz}$ it is evident the random behaviour of these parameters, meanwhile below $100 \mathrm{mHz}$ we can observe a polarization pattern of the signals.

In Figure 11 it is evident that the direction of the polarization ellipse (almost linear) is oriented NorthWest/South-East, i.e. the orientation angle $\theta$ is about $45^{\circ}$ (with magnetic data the directional ambiguity of $\pm \pi$ remains). The polarization arrow points toward the nearest electrified DC railway Roma-Avezzano-Pescara (see Figure 3a), indicating that the major source of noise comes from this railway line; the nearest track is from Sante Marie to Popoli (see Figure 3b) and within this one an angle of orientation of $-45^{\circ}$ corresponds well to the Basin of Fucino. In fact in order to identify the direction of origin of most noise is very important to consider the geological structure of soil under the track in addition to the distance of the electrified railway from the observatory.

Figure 13 shows the distribution of the polarization parameters on the example day (January 13, 2007); the polarization degree exhibits a Rayleigh distribution with maximum around 0.25 . The ellipticity seems to
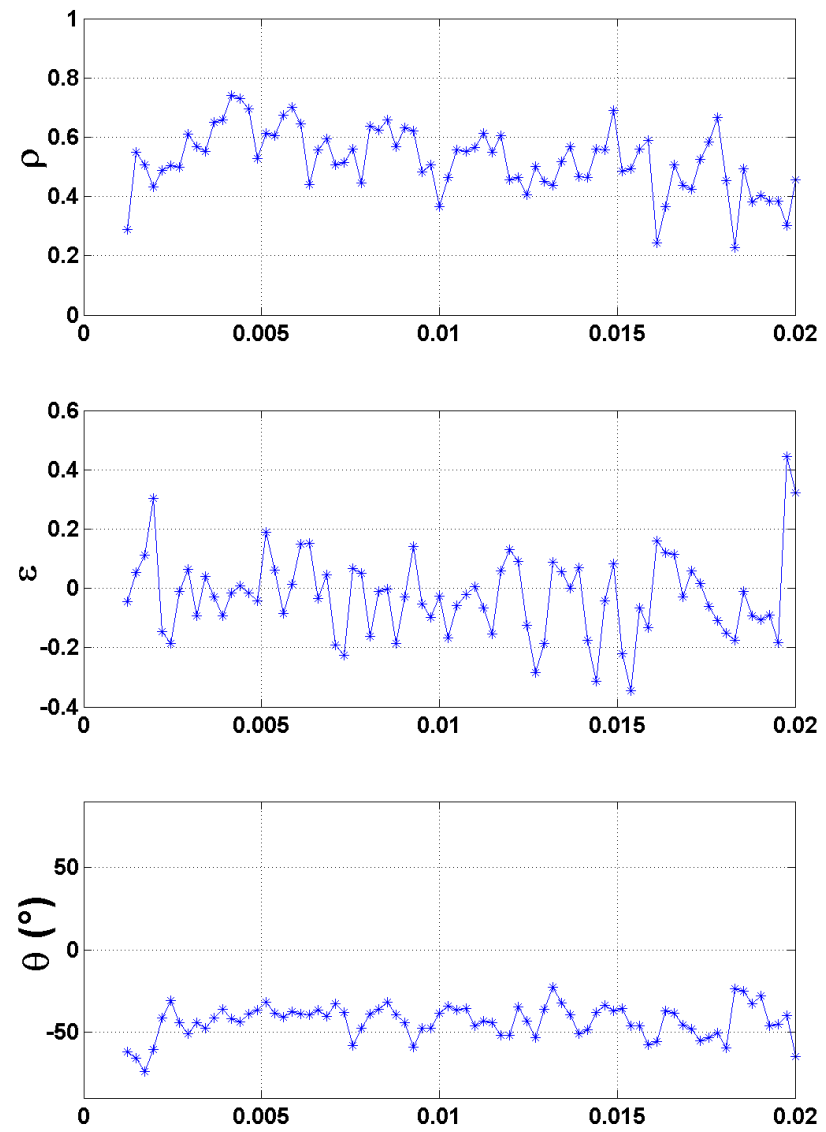

$f(H z)$

Figure 11. Enlargement of the coherence analysis in the frequency band up to $20 \mathrm{mHz}$.

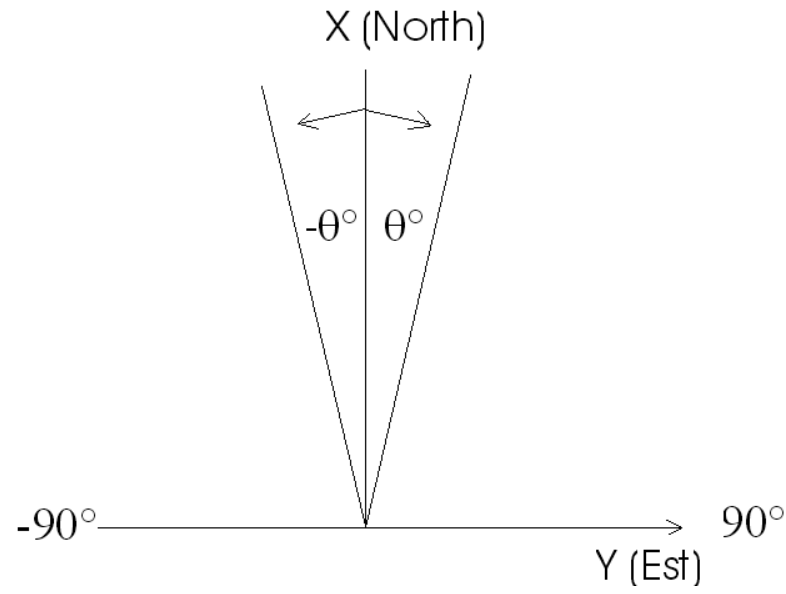

Figure 12. Scheme of the orientation angle.

have a Gaussian distribution with maximum around zero, indicating a dominant linear polarization.

Figure 14 represents the probability distribution of signal amplitude of the three components $\mathrm{H}, \mathrm{D}, \mathrm{Z}$; this distribution is strongly Gaussian for all components and this fact is due to the overlapping of $\mathrm{n}$ independent signals sources.

In Figure 15 the noise distribution in cylindrical co-
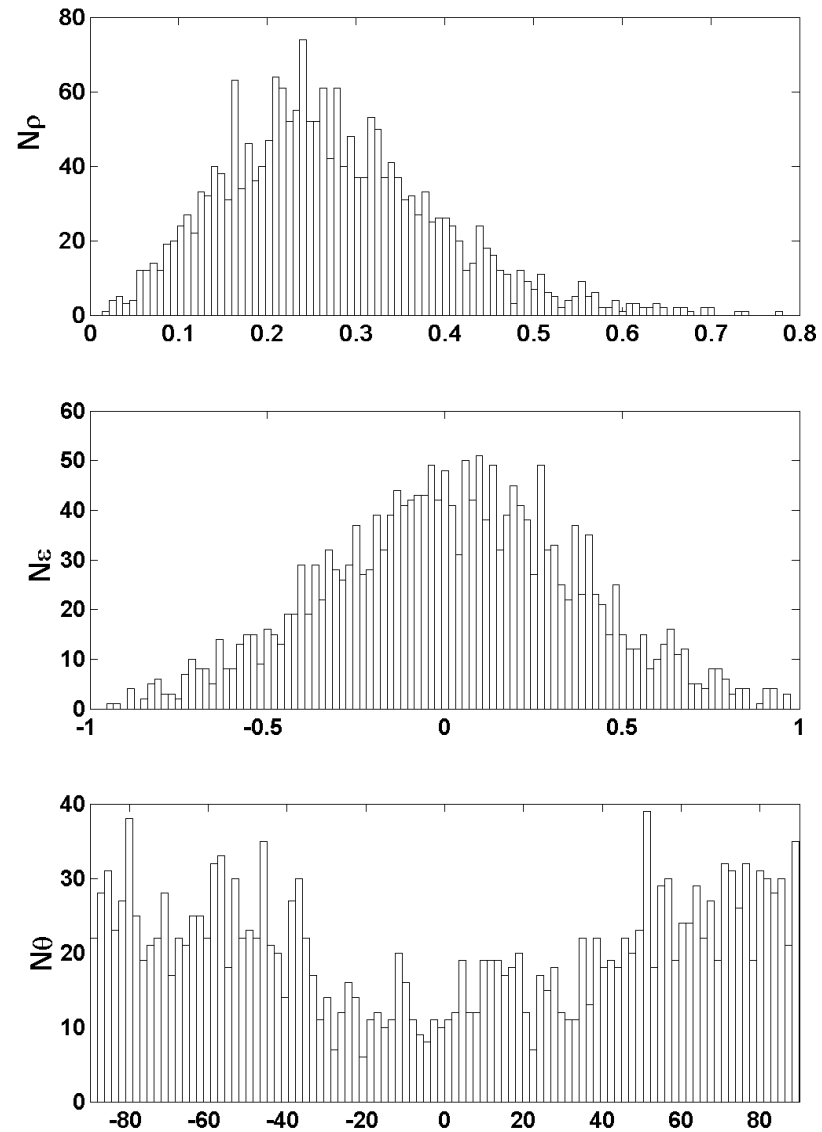

Figure 13. Distribution of the polarization parameters. 

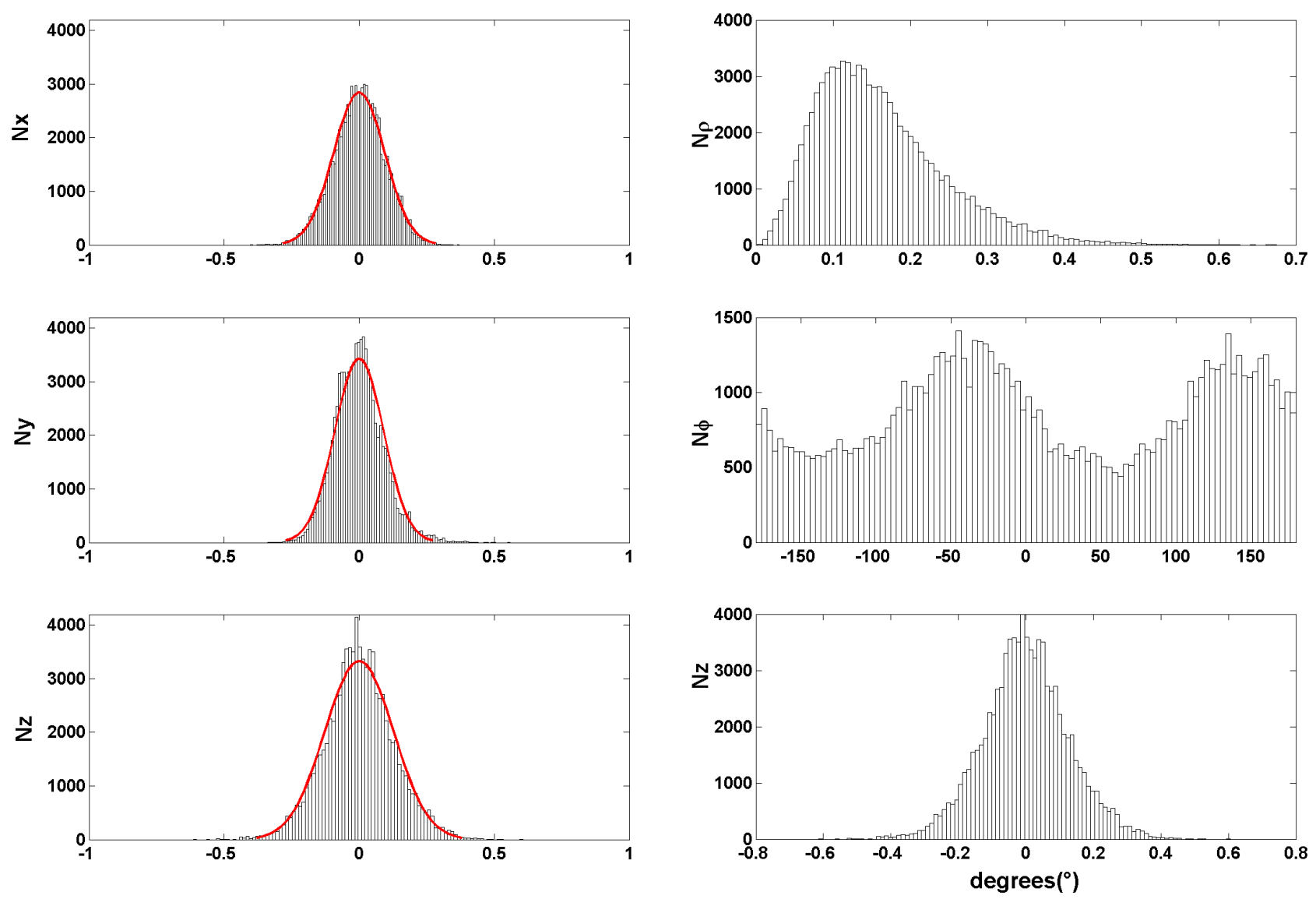

Figure 14. Probality distribution of signal amplitude.

Figure 15. Noise distribution in cylindrical coordinates.

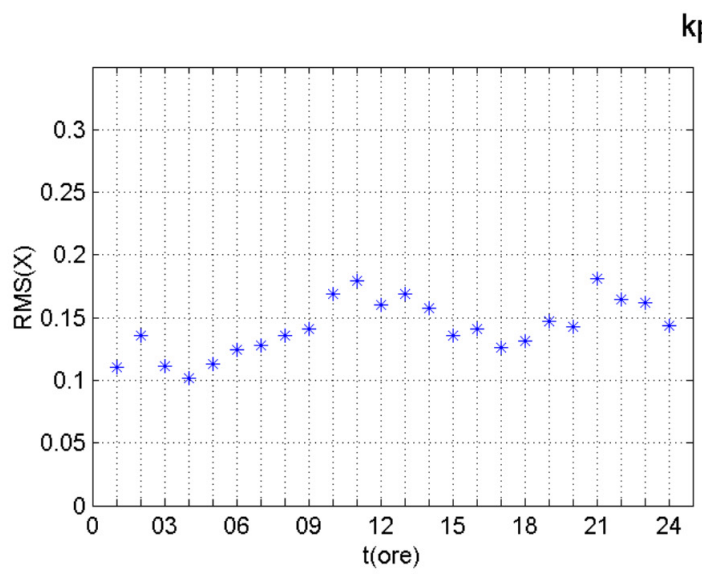

$\mathrm{kp}=0(2006+2007)$
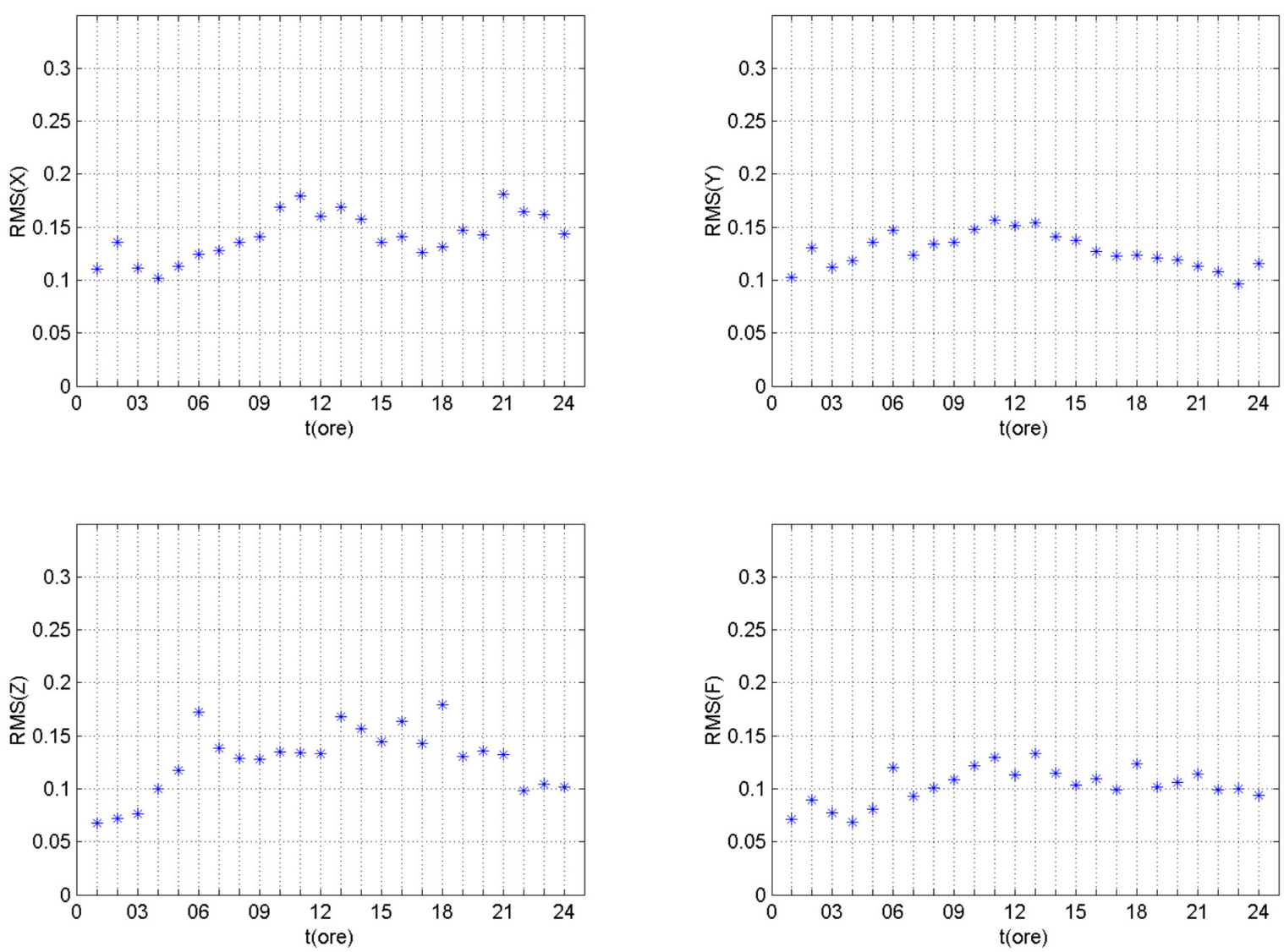

Figure 16 (left and right panels). Daily distribution of RMS during 2006 and 2007. 
ordinates is presented. The radial component is characterized by Rayleigh distribution as expected by the theory [Kendall and Stuart 1973, Bendat and Piersol 1986, Larsen and Marx 1986, Johnson et al. 1994]. The axial distribution is Gaussian and azimuthal distribution has two maxima with a phase difference of $\pi$ which represent the direction North-West/South-East [Cartwright and Longuet-Higgins 1956].

\section{Statistical analysis}

We conducted a statistical analysis of $1 \mathrm{~s}$ data relative to years 2006 and 2007, selecting periods with local $\mathrm{K}$ index around zero.

Figure 16 shows the daily distribution of rms of components value, on a hourly base, during 2006 and 2007, indicative of the noise (by taking into account the selected low $\mathrm{K}$ values) during two years.

In the upper-left panel we can see that in the NorthSouth direction the maximum fluctuation of the signal is centred around noon, while in the East-West component is observed during the morning. In the vertical component there are two maxima around $6 \mathrm{UT}$ and $15 \mathrm{UT}$.

Anyway, in all components during the night from 23 UT to 03 UT the noise reaches minimum values, possibly due to the fact that the nearest railways system ( $\sim 33 \mathrm{~km}$ from the observatory) is switched off.

\section{Time distribution of the noise}

Both local noise and the external natural signals are characterized by a large diurnal fluctuation with a remarkable consistency of phase between $1 \mathrm{mHz}$ to
$0.5 \mathrm{~Hz}$, as showed in Figure 17, where the root mean square value (i.e. the integrated value of the square of the field) on 5 seconds in four different frequency bands is showed. In this figure we can observe that the signals decrease with increasing frequency.

In Figures 18, 19 and 20, where we show the temporal distribution of the electric field, the diurnal variation of the background electric field noise and of the magnetic field noise, respectively, we can clearly observe time intervals in which the noise reaches minimum intensity.

It is very important to identify the most suitable time and frequency window by means of long and continuous records of measurements in the frequency band of interest. By analysing several years of data it is possible to determinate a typical noise's trend with 24-hours periodicity, clearly related to anthropic activities. This temporal window has stationary characteristics, i.e. it does not change with time. Figure 17 shows that in $0.1-1 \mathrm{~Hz}$ band the spectral power reaches a minimum value; in this frequency band the noise has white pattern characteristic and this spectral pattern has stationary characteristic.

In Figure 18 the typical daily variation of the electric spontaneous field is shown (one second data); we can observe that during the night hours (21:0003:00 UT) the electromagnetic noise reaches minimum values, possibly in correspondence with the minimum of the industrial activity in the Central Italy. On the other side the shift between red and blue curves is possibly due to the thermal effects on the

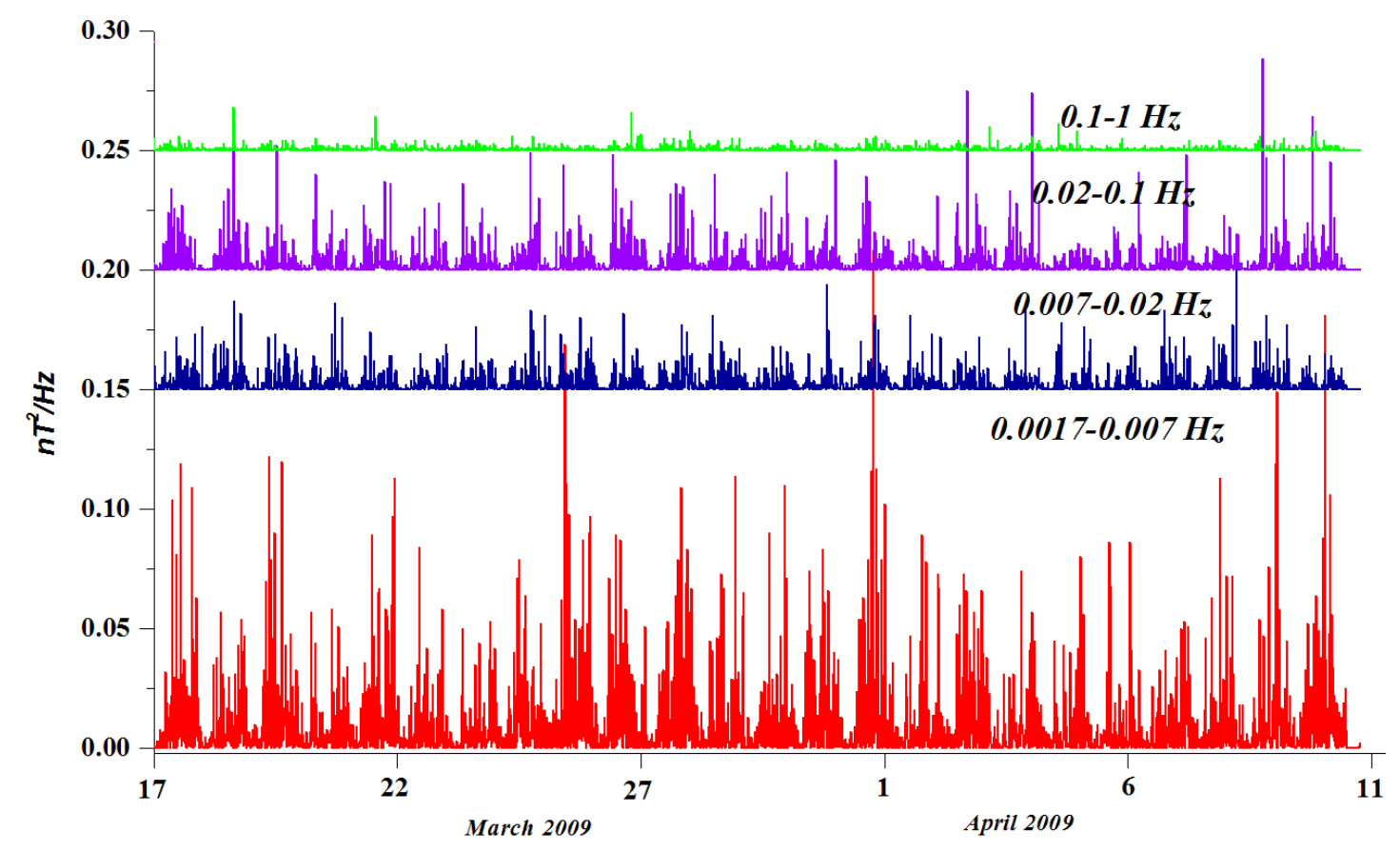

Figure 17. Diurnal variation of magnetic intensity field (component Z) observed at L'Aquila in the frequency band from $0.0017 \mathrm{~Hz}$ to $1 \mathrm{~Hz}$, not scaled adopted from Di Lorenzo et al. [2011]. 


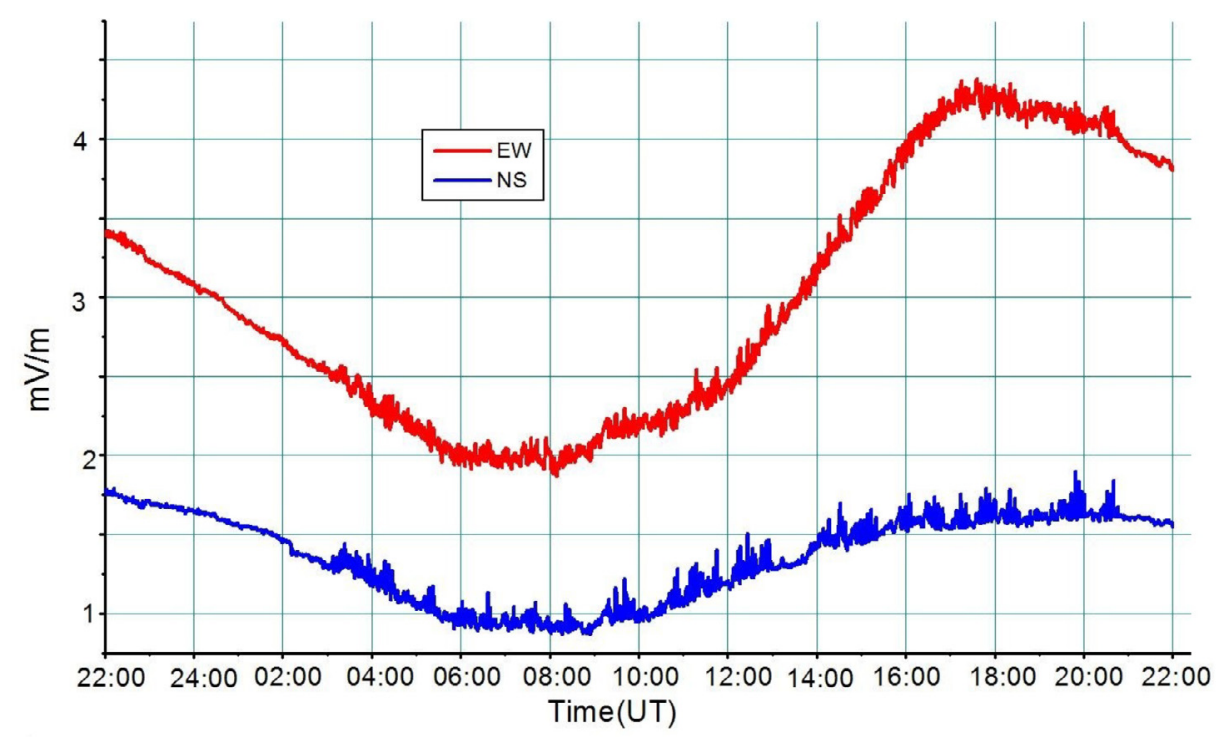

Figure 18. Time distribution of the electric field.

ground layer and to the electrodes. This effect is different on the two components, indicating a possible ground anisotropy in the two directions.

Figure 19 shows the electric field filtered in the frequency band from $0.001 \mathrm{~Hz}$ to $1 \mathrm{~Hz}$. Even in this picture it is evident that at L'Aquila Geomagnetic Observatory the weakest background noise level occurs between 21:00 and 03:00 UT (more clearly on the electric field than the magnetic one, Figure 20, from Di Lorenzo et al. [2011]. In this time interval the noise is much lower than during the day, about ten times, possibly due to the interruption of the railway traffic during night.

From the train timetables of nearest stations (see Table $1 \mathrm{a}, \mathrm{b})$ we checked that the traffic was interrupted during the night; in particular, within the nearest track from Sante Marie to Popoli (see Figure 3b) the last arrival in the evening is at 21:26 UT (20:26 UT during daylight saving time) at Sulmona station and the first leaving in the morning is at 03:05 UT (02:05 UT during daylight saving time) at Avezzano station, in agreement with our results.

\section{Discussion and summary}

The major sources of electromagnetic noise in the frequency bands concerning magnetotelluric and geomagnetic measurements are given by electric railways. The choice of the locations for the installation of geomagnetic stations on the Italian territory often represents a problem not easily solvable, since the railway network is DC powered; only a few available areas are relatively noise free. Excluding Sardinia, where there is no railway electrification yet, in other regions, even those less crossed by railways and at a low industrialization level, it is very difficult to find places where the electromagnetic background noise level can be compatible with the geomagnetic measurements. The ef- fects of the electromagnetic field produced by the electric railways is a source of serious artificial disturbance for natural magnetic and electric fields measurements even if the observation station is situated some ten kilometers away from the big railways.

In the observatory, in this frequency band, routine measurements of magnetic field, electric conductivity of the subsoil (by means of GDS techniques), electromagnetic field and magnetotelluric investigations are usually conducted.

The man made magnetic noise is the main source of the interference that hardly limits the discrimination of the signals in the different field of investigations, in particular during the diurnal hours, when the noise is higher. The anthropogenic electromagnetic noise, such as power lines, DC railways, factories, etc., generates signals whose amplitudes are often higher than those of natural signals and in the same frequency band [Fraser-Smith and Buxton 1975, Yanagihara 1977, Fraser-Smith and Coates 1978, Lanzerotti et al. 1990, Lowes 2009]. These sources of noise are of local nature, so they could be hardly distinguished from signals of magnetospheric origin [Lokken and Shand 1964, Fraser-Smith and Coates 1978]. Both background local noise and signals of external origin are characterized by a large diurnal periodicity, with remarkable consistency of phase. In general man-made disturbances are expected to perturb electromagnetic measurements on a wide range of time scales, at least from daily to seasonal. On the other hand natural signals are also expected to show daily, seasonal and solar cycle variations [Jacobs 1970].

In our work we analyzed electromagnetic background noise at L'Aquila Geomagnetic Observatory during years 2006 and 2007, in the frequency band 1 $\mathrm{mHz}-100 \mathrm{mHz}$. 


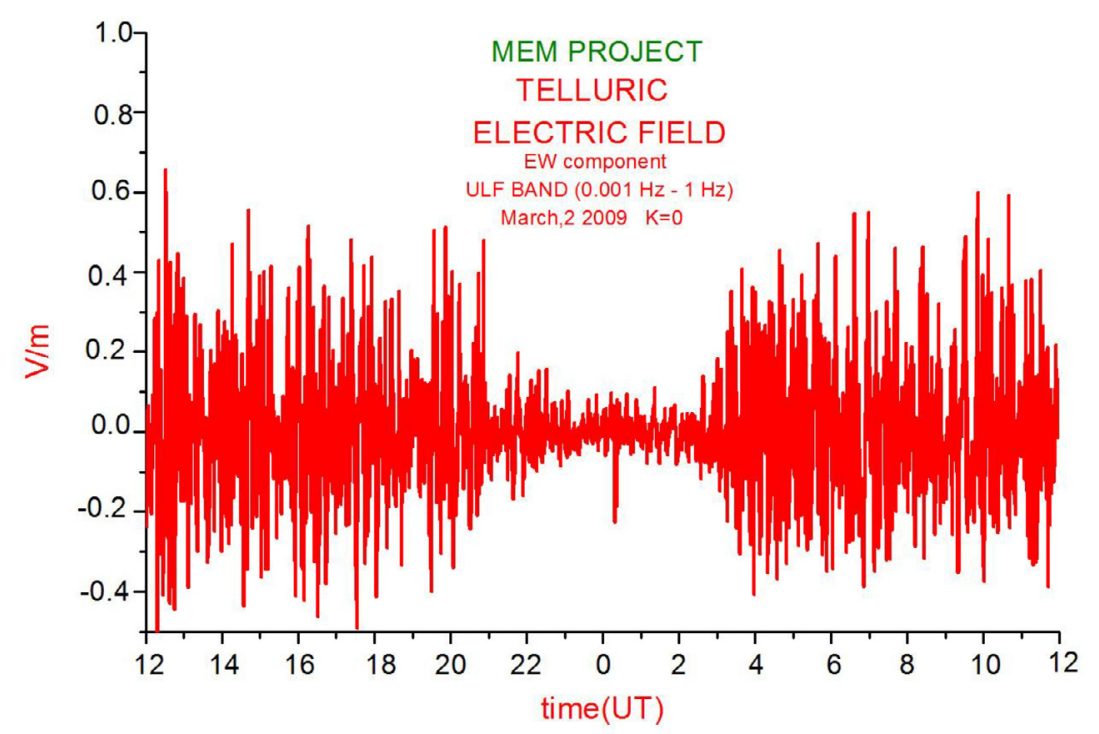

Figure 19. Diurnal variation of electric field noise adopted from Di Lorenzo et al. [2011].

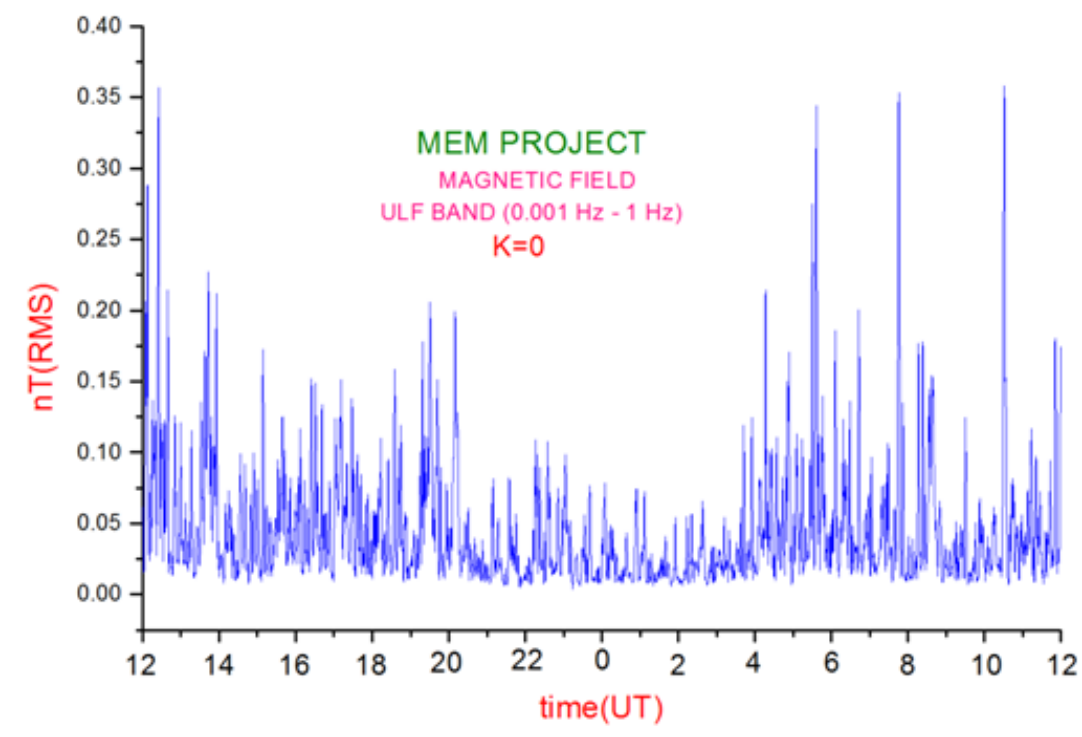

Figure 20. Diurnal variation of magnetic field noise, component $Z$ adopted from Di Lorenzo et al. [2011].

In order to separate noise from signal we analyzed periods when the local $\mathrm{K}$ index approximately was zero, that is when the natural magnetospheric and ionospheric activity is minimum.

An interesting result is that the value of the orientation angle of the polarization ellipse is $-45^{\circ} \pm \pi$, i.e. the polarization arrow points toward the nearest electrified DC railway Roma-Avezzano-Pescara (see Figure 3a), indicating that the major source of noise comes from this railway line, in particular from Basin of Fucino.

From Figure $3 \mathrm{c}$ is evident the hydrogeological nature of this area: the wide basin of Fucino until 1875 was a lake, the third largest of Italy (drained because no effluent and during periods of heavy rains the waters overlowed causing damage); the subsoil is rich of clay materials and lacustrine sediments with high electrical conductivity, as is known [Bussian 1983] due to their particular internal structure with a parallel arrange- ment of multilayers of silica, aluminum and magnesium creating a negative charge cloude on the surface of clay [Iliceto et al. 2003] triggering the electrical surface-conduction. For this reason a clay soil structure is generally a good conductor with a low value of resistivity equal about to (5-20) $\Omega^{*} \mathrm{~m}$, instead rocks behave as isolant with much higher values of resistivity due to their characteristic crystalline structure without electrical charge free to move when subjected to a potential difference (for example calcium carbonates have value of resistivity equal to $1000-5000 \Omega^{*} \mathrm{~m}$ ).

On the right of the Basin of Fucino is situated the Peligna Valley (see Figure 3c) that also was occupied by a vast lake in prehistoric times; in fact its name comes from ancient greek peline (pelagus) and means muddy or slimy ground, but actually the thickness of this lake sediments is thinner than Fucino.

Therefor, in order to identify the direction of origin 

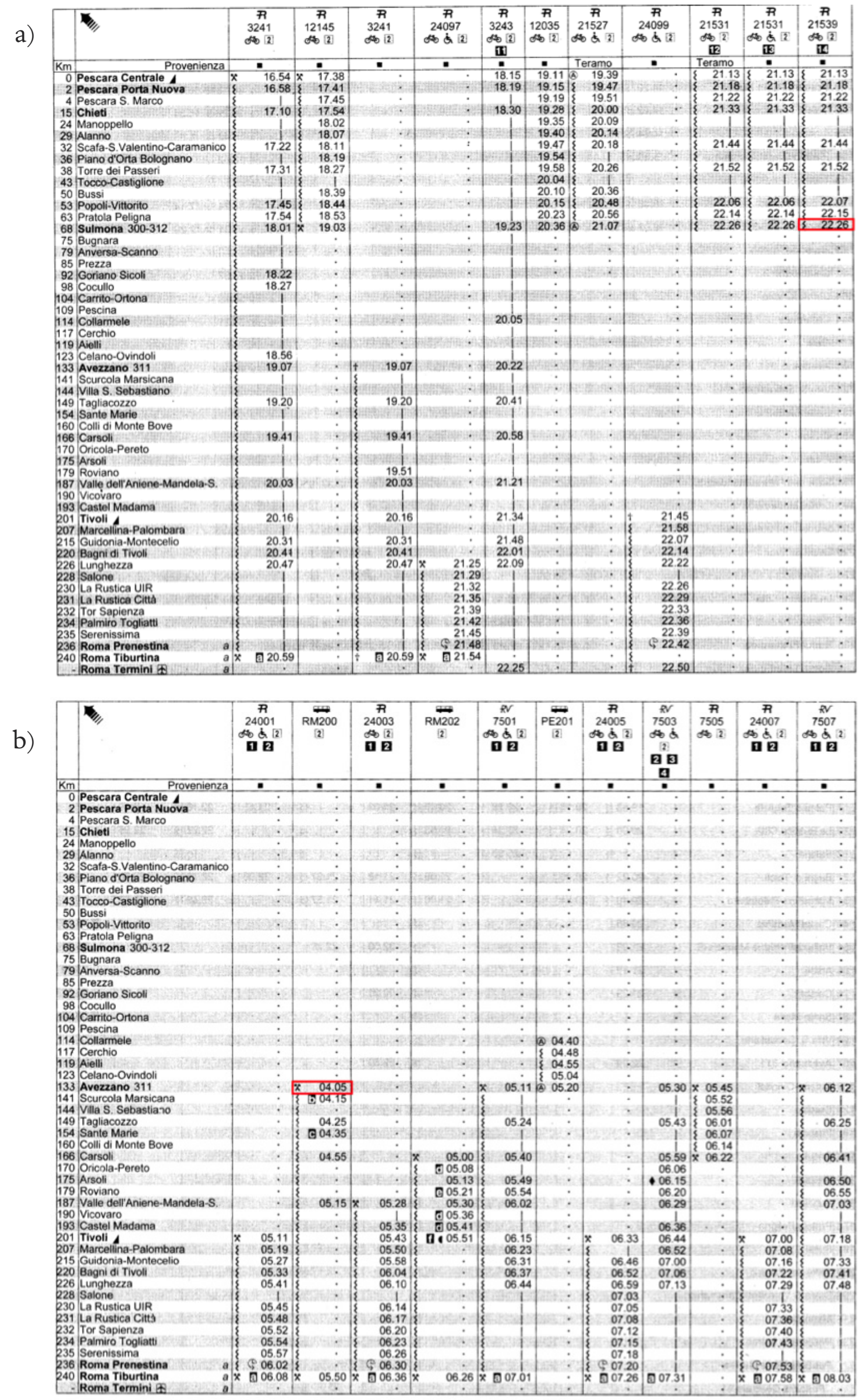

Table 1. Timetable of railway stations: in red, the last arrival in the evening (a) and the first leaving in the morning (b) within nearest track to L'Aquila observatory. 
of most noise is very important to consider the geological structure of soil under the track in addition to the distance of the electrified railway from the observatory.

Another interesting result is that at L'Aquila Geomagnetic Observatory the weakest background noise level occurs between 21:00 and 03:00 UT; in this time interval the noise is much lower than that during the day, about ten times. This reduced power level found during the night agrees with the study of Villante et al. [2004].

From the statistical analysis it's possible to observe that in all components, during the night, the noise reaches minimum values, in particular on $Z$ component, and this is possibly due to the fact that the nearest railways system ( $\sim 40 \mathrm{~km}$ from the observatory) is switched off, as verifiable in Table 1a,b.

Still on the $Z$ component it is evident the characteristic daily variation, with a minimum around the local midnight and a maximum around noon. The fact that the observed behaviours are more marked on the component $Z$ with respect to the horizontal ones, show that the $Z$ component depends very much on the environmental noise, and is scarcely influenced on the external sources, with that found by Palangio et al. [1991].

Even from the power spectra of the geomagnetic field components (in logarithmic scale, Figures 6 and 7) it is clear that the spectral slope of $Z$ component is higher than the horizontal ones, possibly due to the influence of the conductivity structure of the subsoil; in fact the soil behaves as a low-pass filter that attenuates highest frequencies, increasing the slope of the spectrum.

Acknowledgements. The authors thanks the technical staff of the Geomagnetic Observatory of L'Aquila for their support.

\section{References}

Belyaev, P.P., S.V. Polyakov, V.O. Rapoport and V. Yu (1990). Trakhtengerts: The ionospheric Alfven resonator, J. Atmos. Terr. Phys., 52, 781-788.

Bendat, J.S, and A.G. Piersol (1986). Random data: analysis and measurement procedures, 2nd ed., John Wiley \& Sons, New York.

Burkhart, K. (1951). Erdstrom-Untersuchungen am Erdmagnetischen Observatorium in Fürstenfeldbruck, Geofisica Pura e Applicata, 19, 3-16.

Bussian, A.E. (1983). Electrical conductance in a porous medium, Geophysics, 48, 1258-1268.

Campbell, W.C. (1997). Introduction to geomagnetic fields, Cambridge University Press.

Cartwright, D.E., and M.S. Longuet-Higgins (1956). The statistical distribution of the maxima of a random function, Proc. Royal Soc. London Ser. A, 237, 212-232
Constable, S.C., R.L.Parker and C.G Constable (1987). Occam's inversion: a practical algorithm for the inversion of electromagnetic data, Geophysics, 52, 289-300

Constable, C.G., and S.C. Constable (2004). Satellite magnetic field measurements: applications in studying the deep Earth, Geophysical Monograph series, $150,147-159$.

Di Lorenzo, C., P. Palangio, G. Santarato, A. Meloni, U. Villante and L. Santarelli (2011). Non-inductive component of electromagnetic signals associated with L'Aquila earthquake sequences estimated by means of inter-station impulse response functions, Nat. Hazards Earth Sys., 11, 1047-1055.

Egbert, G.D., M. Eisel, O.S. Boyd and H.F. Morrison (2000). DC trains and Pc3s: Source effects in midlatitude geomagnetic transfer functions, Geophys. Res. Lett., 27, 25-28.

Fowler, R.A., B.T. Kotick and R.D. Elliot (1967). Polarization analysis of naturally and artificially induced geomagnetic micropulsations, Geophys. Res. 72, 2871-2883.

Fraser, B.J., and C.D. Ellyett (1964). Man-made magnetic micropulsations, J. Geophys. Res., 69, 3603-3606.

Fraser-Smith, A.C., and J.L. Buxton (1975). Superconducting magnetometer measurements of geomagnetic activity in the 0.1 -to $14-\mathrm{Hz}$ frequency range, J. Geophys. Res., 80, 3141-3147.

Fraser-Smith, A.C, and D.B. Coates (1978). Large amplitude ULF electromagnetic fields from BART, Radio Science, 13, 661-668.

Iliceto, V., F. Finotti and F. Zandonai (2003). Water content and critical thresholds on embankments through electrical tomography, Geologia Tecnica e Ambientale, 4, 41-51.

Jackson, J.D. (1975). Classical Electrodynamics, 2nd ed., John Wiley \& Sons, New York.

Jacobs, J.A. (1970). Geomagnetic micropulsation, In: J.G. Roeder (ed.), Physics and Chemistry in Space, Springer-Verlag, vol. 1.

Johnson, N.L., S. Kotz and N. Balakrishnan (1994). Continuous univariate distributions, Wiley Series in Probability and Mathematical Statistics, New York.

Jones, F.W., and A.M. Kelly (1966). Man-made telluric micropulsations, Can. J. Phys., 44, 3025-3031.

Junge, A. (1996). Characterization of and correction for cultural noise, Surv. Geophys., 17, 361-391.

Kendall, M.G., and A. Stuart (1973). The advanced theory of statistics, Vol. 2: Inference and relationship, 3rd ed., Hafner Publishing Company, New York.

Lanzerotti, L.J., C.G. Maclennan and A.C. Fraser-Smith (1990). Background magnetic spectra: $\sim 10 \mathrm{E}-5$ to $\sim 10 \mathrm{E}+5 \mathrm{~Hz}$, Geophys. Res. Lett., 17 (10), 1593-1596. 
Larsen, R.J., and M.L. Marx (1986). An Introduction to Mathematical Statistics and its Applications, Prentice-Hall, 281 pp.

Lokken, J.E., and J.A. Shand (1964). Man-made electromagnetic interference at extremely low frequencies, Canadian Journal of Physics, 42, 1902-1907.

Lowes, F.J. (2009). DC railways and the magnetic fields they produce - the geomagnetic context, Earth Planets Space, 61 (8), i-xv.

Märcz, Gy., and J. Verö (1970). Prevention of Electric Disturbances in the Observatory near Nagycenk, In: Geophysical Observatory Reports of the Geodetic and Geophysical Research Institute of the Hungarian Academy of Sciences for the Year 1969, Sopron, 143-146.

Miguel, L. (1964). Perturbaciones Producidas en Corrientes Telluricas por Lineas de FF. CC. Electrificadas, Revista de Geofísica, 23,89-90.

Mikerina, N.V. (1962). The study of interference at the Voyeykovo magnetic observatory, Geomagn. Aeron., 2, 941-944.

Palangio, P., M. Marchetti and L. Di Diego (1991). Rumore elettromagnetico prodotto dalle ferrovie elettrificate: effetti sulle misure magnetotelluriche e geomagnetiche, Atti del $10^{\circ}$ convegno annuale del Gruppo Nazionale di Geofisica della Terra Solida.

Palangio, P., C. Di Lorenzo, F. Masci and M. Di Persio (2007). The study of the electromagnetic anomalies linked with the Earth's crustal activity in the frequency band $[0.001 \mathrm{~Hz}-100 \mathrm{kHz}]$, Nat. Hazards Earth Sys., 7, 507-511.

Qian, W., and L.B. Pedersen (1991). Industrial interference magnetotellurics: an example from the Tangshan area, China, Geophysics, 56, 265-273.

Szarka, L. (1988). Geophysics aspects of man-made electromagnetic noise in the earth: a review, Surv. Geophysics, 9, 287-318.

Verö, J. (1986). Experimental aspects of low-latitude pulsations - a review, J. Geophysics, 60, 106-119.

Vezzani, L., and F. Ghisetti ( 1996). Carta Geologica dell'Abruzzo, Scale 1:100,000, S.EL.CA., Firenze.

Villante, U., M. Vellante, A. Piancatelli, A. Di Cienzo, T.L. Zhang, W. Magnes, V. Wesztergom and A. Meloni (2004). Some aspects of man-made contamination on ULF measurements, Annals of Geophysics, 22, 1335-1345.

Yanagihara, K. (1977). Magnetic field disturbance produced by electric railway, Mem. Kakioka Mag. Obs., $38,17-34$.

Yumoto, K. (1988). External and internal sources of low-frequency MHD waves in the magnetospherea review, J. Geomagn. Geoelect., 40, 293.
${ }^{\star}$ Corresponding author: Lucia Santarelli, Istituto Nazionale di Geofisica e Vulcanologia, L’Aquila, Italy; email: lucia.santarelli@ingv.it.

(C) 2014 by the Istituto Nazionale di Geofisica e Vulcanologia. All rights reserved. 